The Field of Inter-organizational Relations

A Jungle or an Italian Garden?

Steve Cropper

Mark Ebers

Chris Huxham

Peter Smith Ring

One of the more pleasant challenges associated with editing this kind of Handbook is being open to the very real likelihood that what we thought we knew, individually and collectively, about Inter-organizational relations would be seriously challenged in the work undertaken by our authors. We did indeed find 'ahas' in each chapter, but the insights also affirmed our a priori sense of IOR as evolving as a field of study. We begin our closing chapter with a review: this includes an appraisal of the 'state of the art' but we are more concerned to look forward, drawing implications of end p.719

This Handbook's assessment of current knowledge for future research into IOR. We then analyse whether the chapters in the Handbook suggest an optimistic picture in regard to the sense of a rather fragmented (silo-like) field structure that we reported in the introductory chapter. Drawing upon that analysis, we close the book by considering how IOR is developing as a field of study.

IOR Research-Now and the Future

Each chapter in this Handbook contains an explicit assessment of priorities for future research that would extend and deepen an understanding of IOR. Given the diversity of contributions to this volume, it is perhaps not surprising that recommendations for future research are varied. And because the three sets of contributions start from different points - empirical manifestations, theoretical and disciplinary perspectives, and thematic interests - so the recommendations, too, might be expected to lead along different paths, 'cutting' and framing future research topics in different ways. Nevertheless, as others have suggested (Brass et al. 2005) it is possible to see some points of convergence across all three parts of the Handbook. We begin our discussion of the contributions and suggestions for the future by focusing on these points of convergence. We then look in turn at the specific ideas that emerge from, and relate to, the specific framings of each of the parts. Finally, we draw together insights about methodological issues.

\title{
Points of Convergence
}

As the extant research on IORs reflected in the chapters of the Handbook clearly demonstrates, organizations that participate in IORs are motivated to do so for a diverse set of reasons. Business firms continue to form IOEs in pursuit of resources that they need for strategic reasons but do not have or cannot make. But they also participate in IORs with organizations from other sectors of the economy with increasing frequency as they seek to deal with other, and increasingly more active, stakeholders of the firm. Governments, and governmental agencies, employ IORs not only to share scarce resources in service delivery, but also to create new resources. In 
this respect, their motivations in relying on IORs are not very different from those of counterparts in the private sector. And as issues that confront societies become more complex and multifaceted, we find IORs (and IOEs) in which firms, public agencies, non-profit-making organizations, and non-governmental agencies are engaged in seeking solutions to issues such as climate change, health care, educational reform, etc. In short, it is clear that the basis for collaboration among and between organizations is institutionally much more developed today than it was when scholars initially began to focus on them in the 1960s and 1970s.

Those who have focused on why organizations collaborate have provided us with a much better understanding of the kinds of resources that collaborators seek. This is particularly true in the case of knowledge, especially when so-called 'tacit know-how' is sought by one or more organizations engaged in IORs. What we know in this area is also a function of the kind of theory that is being employed. The frequent use of transaction cost theory (TCT) (see Hennart, this volume) as a lens through which to study collaborations is one reason why we know so much more about resources than other reasons why organizations collaborate (e.g. the pursuit of greater political power by business firms). The theory of the resource-based view of the firm has also produced a more refined understanding of why and how a search for resources leads to IORs, in part as its advocates contrast it with TCT and in part because of its frequent use in studies into the use of IORs for purposes of learning and/or innovation (see Nooteboom, this volume).

As the nature of the content of relationships between organizations has become more complex, so has the structure of those relationships. Thus, the chapters in the Handbook report increased empirical evidence of, and research on, private sector IORs involving multiplex objectives and relationships such as: business groups, chaebol, consortia, cooperatives, constellations, federations, inter-firm networks, keiretsu, network organizations, and so on (see e.g. Gomes-Casseres 1994; Jones et al. 1998; Granovetter 2005). And as Geddes, Klijn, Knoke and Chen, and Sand-fort and Milward clearly demonstrate in their contributions to this volume, these multiplex structures manifest themselves in the public sector as well.

We started the Handbook by stipulating that a fundamental building block for IORs is the dyadic or multilateral relation. Dyads certainly persist as a key unit of analysis and for many important reasons continue to be the dominant form of IORs under study by scholars. As a result we have some understanding of the impact that asymmetries such as different partner organizational structures (tall versus flat) or types of organizations (functional start-ups collaborating with MNCs) have on the structure of IORs. We know much less, however, on how differences in structure play out in networks involving large numbers of organizations. There appears to be a strong trend in attention towards such aggregates of IORs - networks, fields, domains, communities, and populations. Whilst these offer both interest, in themselves, and explanatory power, the increase in research on these kinds of IORs is perhaps also due to the development of powerful analytical tools designed to identify the existence of networks among organizational actors, to define the structure of those networks, and to explore how such structures change over time (see e.g. Freeman 2004; Moody et al. 2005; de Nooy et al. 2005). In reviewing the work of the authors found in Part II of the Handbook, we conclude that the use of this approach and unit of analysis is much more prevalent in studies of private sector organizations than in the case of those in the public sector (though see Klijn, this volume, for a discussion of its developing use 
in the study of policy networks). There is also some recent work that privileges other units of analysis. For example, although we do not yet see Simmel's (1950) preoccupation with the properties of the triad becoming a strong feature of IOR research, more attention to 'third party roles', triad formations, and the effects of the third party both on dyads and on wider systems of IOR would seem justified, as Bachman and Zaheer noted in their discussion of trust (see also Caplan 1956; Burt 1997; Gulati and Gargiulo 1999; Obstfeld 2005; Nooteboom 2006).

In choosing which units of analysis to privilege, then, there is agreement that the menu is rich and that care is required. There are calls for more rigorous thinking about the character of each unit and about the way in which relationships between different levels of analysis are theorized and investigated. IOR research is increasingly bridging different levels and units of analysis. As Brass et al. (2005) argue, 'understanding network change requires understanding cross-level pressures'. They point to consequential linkages between individual, group, unit, organizational, Interorganizational, and contextual actors and to some shifts in emphasis that signal a greater refinement in organizational network research. In their chapter on evolutionary theory, Lomi, Negro, and Fonti talked of the Chinese box-like character of intra- and Inter-organizational hierarchies (which) implies that evolutionary change is essentially a multilevel process: what happens at one level is difficult to understand without reference to what is happening simultaneously at lower and higher levels of aggregation ...For this reason, many questions remain open about the appropriate level and unit of evolution in organizational research.

Kenis and Oerlemans in this volume also reveal the extent to which the concepts of social network theory have contributed to our understanding of the structure of relations among and between organizations.

Given the increased complexity of the reasons why organizations are collaborating with each other, and the concomitant complexity of the structure of these relationships, one might expect to find similar degrees of variety in the governance of IORs. Our sense of the research, however, suggests that this is not the case. Unified governance (Williamson 1985) persists in the case of equity joint ventures. Bilateral and trilateral approaches to governance also manifest themselves as governance mechanisms in the case of many strategic alliances (in which a written contract remains the primary approach to memorializing such agreements). Nonetheless, the network appears to be an increasingly important approach to the governance of IORs, both in practice and in theory (see e.g. Rowley et al. 2000).

The topic of trust as an approach to governance is, without question, one of the most intensely studied aspects of IORs. The roles that incentives play in governing IORs have been less studied than trust, although more of in the case of dyads than in the case of networks. Surprisingly, less attention has been paid to reciprocity as a governance mechanism than one might have expected (except as it relates to the formation of trust). Where attention has been paid, it tends to emerge as a factor in studies that explore the role of social capital in the formation and evolution of IORs (see Nahapiet, this volume). Finally, studies of the governance of IORs have produced much greater understanding of the ways that administrative controls function in the governance of IORs, particularly in public sector policy networks and public sector service delivery collaborations.

Having provided a brief, general assessment of what is available to those interested in the study of IORs in this volume, we will now turn our attention to somewhat more 
specific syntheses of the work undertaken by contributors to the Handbook. We will deal with each of the three main parts of the Handbook in the following discussion. Empirical Manifestations

We have given some sense of where empirical knowledge about IOR has started to accumulate in the section above. Whilst there has been a steady accumulation of findings, such as those we have described above related to content of relationships between organizations, the structure of IORs, and the ways in which they are governed, equally, there are many gaps in knowledge, and important points of uncertainty and disagreement to address.

Many of the contributions have started from a view that IORs are increasingly common organizational forms. If the prevalence of IOR is increasing, then two sets of questions are raised. First, descriptively, how significant a presence in the populations of organizational forms and organizational behaviours are IORs? And if, as many contributors to this Handbook have argued, the trend has been one of continuous growth in the formation and continuing existence of IORs, what is the evidence? Studies of populations and communities of organizations that have included measures of IORs (e.g. Granovetter 2005; Saxenian 2006) have been a useful first source of evidence, but longitudinal studies that confirm the prevailing arguments about trend are needed to validate assertions and add to our understanding of the patterns of formation, continuation, and density of IOR. And, as well, precisely what types of IOR are observed in what kinds of contexts? Lazerson and Lorenzoni give us some sense of what appears to be happening to the changing nature of IORs in Italian industrial districts. Yet it remains to be seen if this is transitory or if it reflects a pattern that will be found in the future in other districts in other countries. These questions of measurement and description are challenging conceptually and methodologically. How should IORs, IOEs, and populations or communities of organizations be defined for the study of IOR? This question is important since IORs start to challenge received classifications of organizational domain and raise questions of hybridity: the identity of organizations engaged in IOEs is both placed in sharp relief, and subject to change, as the relationship between them develops. Mandell and Keast make the point most forcibly in their chapter, by reviewing the variety of ways in which voluntary and community organizations are now relating to public sector (and business) organizations. Indeed, categories such as 'community enterprise' and 'non-profit business' already blur these identities. And Mandell and Keast ask (rhetorically) whether there is a need for a new language of IORs, especially to describe the new relationship between VCOs and the government. Whilst a more generalized knowledge of IORs may be starting to appear, there remains a strong sense in which the character of IORs and the identity of partner organizations are still strongly rooted in particular and historically significant institutional contexts. For example, Klijn's argument about the importance of work to explore forms of democratic network governance is not mirrored in Lazerson and Lorenzoni's review of industrial clusters or Johnsen, Lamming, and Harland's review of business networks, where stakeholder theory and ideas of accountability have, as yet, no clear equivalent. It is not simply cross-sectoral difference that is important here. Although Nooteboom does suggest paying more attention to the nature of the industry in which a network approach to innovation is employed, Nooteboom also concludes that attention to types of technology and knowledge is likely to increase our understanding of the role of IORs in fostering innovation and learning. 
The second set of questions is to do with explaining how IORs form, stabilize and are sustained, or change and with understanding the effects of IORs. As Ebers (1999) pointed out, there is a basic analytical division between endogenous explanations that locate agency within the component parts of an IOE and exogenous explanations that point to IOEs as responses to pressures in a wider context. The discussion of IORs in IT-related industries by Hui, Fonstad, and Beath provides evidence that IORs amd IOEs in those industries are responses to outsourcing of what once was considered a source of competitive advantage for many firms. In practice, IOR research may give privilege to one or the other in the explanatory figure that is offered or developed to frame the research. Or, indeed, explanations may incorporate both exogenous and endogenous factors. The chapters in Part II provide many examples of specific ways of addressing questions of this sort. For example, Lazerson and Lorenzoni's analysis pointed to the linked changes in the form of IOEs and the institutional contexts in which they are situated. They suggested, our understanding of the contribution of industrial districts, local networks and traditional community bonds to economic development needs to be revisited ...the argument that interfirm cooperative relationships among roughly egalitarian firms and backed by publicly subsidized innovation centres could invariably produce solutions to each succeeding wave of competitive challenges from low-cost producers seems to be undermined by evidence of the effects of more powerful economic realities.

But they also point to the importance of those 'leading firms' that do survive by building longer-term, complex, and effective relationships into multiple networks stretched across large distances to distributors and markets. In contrast to the conclusion of Johnsen, Lamming, and Harland, Lazerson and Lorenzoni found evidence that the networks that they observed are being managed, and strategically so. Yeung's chapter provides a second example. He asked how future GPN (global production networks) research should address the mutual interdependencies of the social/cultural and the economic, or agency and structure, as the 'economic' is increasingly reconceptualized to incorporate social and cultural dimensions in the 'new economic geography'. His argument is to draw together complementary theories: thus 'political economy has much to offer in terms of explaining the structural and institutional preconditions of human action, while Actor Network Theory ... helps to focus on the agency dimension in producing IORs'.

A third example is provided in Sandfort and Milward's chapter. They questioned how the purpose of collaborative service delivery impacts on its implementation and its consequences. Does the level of partnership - policy, organizational, programme, front-line - and alignment among these levels influence collaboration implementation and outcomes? How does time influence how collaborative structures operate and how they produce results? How should we theorize about the causal mechanisms that link these new service arrangements to tangible results?

A final perspective on explaining how IORs form or are sustained is encapsulated by Johnsen, Lamming, and Harland's note that little research has been conducted which provides a truly comprehensive classification of different types of networks. What might such a research programme include? Klijn offers some suggestions when he notes that further development is certainly needed. First, he argues that there may be justifiable interest in understanding the characteristics of networks and how to analyse 
them: these require theoretical and methodological attention respectively. Second, he suggests, more research is needed to investigate the way that the institutional features of different networks clash - an institutional approach holds out possibilities for separating different network forms. And, Klijn suggests, since any given policy initiative tends to require the involvement of different networks, one way of examining fundamental differences in networks is to explore how policy draws in, or even constructs, different types of network and so exposes graphically the ways in which networks of different types rub up against one another, precisely because they differ in fundamental ways.

\section{Perspectives}

Starting from theoretical and disciplinary knowledge - what we have labelled 'perspectives' in this Handbook - future research directions are equally varied. As the contents of Part III - and our discussion of the framing of topics in Part IV - reveal, the parent discipline of organization studies is both theory - and concept - rich. A central question, then, is how to select from among theoretical and disciplinary orientations. The scope of a perspective - that is, its capacity to provide traction at, and across, different levels and units of analysis - is one obvious way to address the issue.

A second criterion of importance may be the extent to which the theory or discipline has engaged with or has incorporated IOR as a subject. This clearly varies. The majority of perspectives that we have included here have developed their IOR focus quite substantially. Typically, they have taken IOEs both as an empirical matter to investigate from the given perspective and as an interesting application area that can be used as a trigger for the development of new concepts. In these areas, as with the discipline of economics, theoretical options may be relatively easy to assess. By contrast, Schruijer's straightforward conclusion was that 'the psychological study of Inter-organizational relations still needs to be developed'. She argued that we can learn much from the social psychology of intergroup relations since comparable psychological processes may be involved in Inter-organizational relations. The opportunities for contribution to IOR are great, but the challenges may indicate why more has not been done from this base in the past. Problems with working with a social psychological understanding of Inter-organizational relations arise from its focus and methods: its concern with groups rather than organizations; its predominant concern with understanding conflict and conflict reduction rather than cooperation; its emphasis on laboratory work and on 'ad hoc' groups; and, its aim to understand rather than to find out how to work with Inter-organizational forms and how to improve their functioning. With an eye partly on methodological development and partly on the use of theory to illuminate IOR and IOR practices, Schruijer argued that, for psychology, the challenges are to create the conditions in which 'real organizations and their interactions are studied, their relevant histories and future perspectives understood, the dynamics occurring at various system levels looked at ...'.

A third criterion concerns the IOR specificity and relevance of theory and concept. As Lomi, Negro, and Fonti suggest, the general body of concepts in evolutionary theory has clear applicability to IOR but, nevertheless, there remain tests of its relevance.

They note that 'Reaching a detailed understanding of the feedback structures that regulate processes of evolutionary development — or "evo-devo"-is a crucial task for 
contemporary evolutionary theories... and is perhaps the final test for the relevance of evolutionary interpretations to the study of Inter-organizational relations.'

A final criterion might be the extent to which there is potential to add to or enrich understanding — either theoretical or empirical — through processes of elaboration of theory. Anselm Strauss distinguishes between processes of theory 'supplementation' (making a jigsaw piece by piece) and processes of 'intension' (filling out/enriching/complicating/focusing). For example, as Hibbert, Huxham, and Ring suggest in the context of the management perspective, relatively little attention has been paid to the day-to-day management of IOEs. There is much scope for (micro and intermediate scale) research that investigates and conceptualizes how IOE managers spend their time. Equally, they point to the lack of work focusing on affect in IOR and 'the relative paucity of useful theory related to decision-making, ethics, and motivation, all of which seem likely to be important in IOR contexts'.

A debate has been recently initiated about the value of theory to managerial practice; specifically that seeking to explain the performance of strategic alliances. Bell, den Ouden, and Ziggers (2006) are concerned about the lack of accumulation of relevant knowledge in the area of alliance dynamics. Hennart (2006), responding, agrees that research has tended either to produce rather superficial variance theories, based on the cross-sectional analysis of secondary data, or 'vague and complex' process accounts of case studies. But he rejects the charge that there is no relevant research, pointing to what he argues is a powerful and potentially more helpful theoretical base addressing the effects of governance structure of alliances on alliance performance. As the journal editors conclude (Editors 2006), there are dangers in a narrow search for relevant knowledge and in a simple dismissal of the inadequacy of research as a guide to managerial practice. Ring, this volume, makes a similar point with respect to the relative failure of scholars grounded in economics, psychology, or management to incorporate both contract law and contract theory into their arguments about the governance of IORs and IOEs. Both theoretical inquiry and relevance challenges, then, can usefully clarify limits, on the one hand, to the range of convenience of any one theory and to the importance of theory selection, and on the other hand, to the possibilities of linkage to improve the explanatory or prescriptive plausibility of theory.

\section{Topics}

Topics are a potentially important part of the agenda for future research. As we have seen in Part IV, they provide a way of framing questions both about the empirical manifestations of IOR and about theories that are employed in studies of IOR. In particular, topics raise questions about the comparative value of different perspectives, the ways in which theories might complement one another, and the potential for integration of theories into our understanding of IOR. They also highlight the difference that institutional contexts might make to the character or fabric of IOR and raise questions about the extent to which knowledge can be generalized across manifestations. The introduction to Part IV indicated a number of 'gaps' in this Handbook's coverage of IOR research, but also suggested that, despite reference to the phenomena, there is little knowledge yet to gather in relation, for example, to Inter-organizational identity, communication and goal negotiation, emotion, accountability, rupture and repair, and ethics. 
Where research has, by comparison, been more substantial, future research might start equally well from empirical or from theoretical questions. Starting from the empirical, Huxham and Beech suggest, there is scope for further investigation of power in IORs. In particular, they point to what they term 'macro-power' as it occurs in different circumstances and given a presumption of multiple types of power source. This is consistent with Knoke and Chen's reading of the future research agenda from a political perspective, in which they argue that empirical studies should seek to identify which power sources - resources, regulations, or networks - weigh more than the others. But Huxham and Beech also suggest that the concept of micro-power warrants further investigation. This might involve a close examination of relational processes and the individual power implicit in them as well as attention to different empirical contexts. And they suggest, too, that there is scope for investigation of the relationship between macro-and micro-power.

Starting from questions raised by theoretical contest over the character and importance of trust in IOR, Bachmann and Zaheer's discussion of the research agenda recognizes the sometimes conflicting assumptions and premises of different disciplinary approaches. Bachmann and Zaheer suggest that a detailed examination of the role of trust in Inter-organizational relations from both the economic and sociological perspectives might be the most fruitful focus for work to explore and potentially reconcile differences/conflicts and so pave the way to a deeper understanding of the issues in this context. We agree and also agree that, in turn, such understandings could help identify appropriate research questions to better empirically investigate the precise role of trust in Inter-organizational relations and differences in the sources, meaning, degree, and outcomes of Inter-organizational trust in different national contexts. This might be revealed most powerfully, providing both theoretical and substantive insight, when IORs bridge contexts where trust differs in degree and meaning. Bachman and Zaheer suggest that such research will need advanced methodologies, such as repertory grid technique.

One likely point of convergence in these kinds of diverse interests (as well as others) is between scholars concerned with power and trust as central qualities of relationships and Inter-organizational processes that approximate to outcomes, such as learning and innovation. Nooteboom demonstrates that the roles of IORs in facilitating innovation and learning within and between firms is critical as the costs and risks associated with innovation increase and as firms become more specialized. He argues that an important shortcoming in the extant research is a failure to more extensively explore relationships between issues of competence of the parties and the governance of their relationships. In particular, he observes, there is a need to reconcile contradictory findings in research dealing with the nature of network structure and the strength (or weakness) of network ties. He observes that tradeoffs are an inevitable consequence of reliance on networks and suggests that more attention be paid to explorations of the implications of seeking optimal rather than maximum flexibility and variability in relations between partners to dyads and/or members of networks. Finally, as we observed above, he advocates greater attention to triads, since these provide a context in which relational practices are likely to be especially rich.

Social capital reflects another topic on which scholars interested in explanations for increased reliance on collaboration have begun to converge. As Nahapiet demonstrates, it has been employed by scholars in economics, sociology, political 
science, as well as in organizational and management studies. In each of these disciplines, definitions of the topic have been 'massaged' to fit with existing assumptions but looking at them collectively can provide scholars interested in its application to an increasingly varied array of IORs and IOEs with a means of crossing sectoral boundaries with greater ease.

Provan and Sydow note that 'performance is something of the Holy Grail of IOR research': although combinations of structure, process, and outcome measures may be available and capable of measurement, the choice of indicator needs to be carefully made. Like Gray and Cropper and Palmer, whose chapters work through theory dependence in systematic fashion, they argue that the choices of measure should be coherent theoretically and this, in the absence of good experimental or quasiexperimental controls, may provide some basis for attributing change to the distinctive contribution of the IOR. Provan and Sydow also suggest that it is helpful, and potentially necessary, to assess performance at multiple levels of analysis - the organizational and inter-organisational levels at least.

Future Research Strategies and Methodology

The question of research strategy and method is one which has not been separately or explicitly treated in the Handbook. However, a number of contributors note the need for further development of methods and the broadening of strategies for inquiry. That the area is largely devoid of comparative assessments is noted more than once. Hibbert, Huxham, and Ring noted, in the context of the management perspective, that 'there are few cross-sector assessments of how managers treat issues such as "partner" selection or trust building'. Jones and Lichtenstein commented that 'few comparative studies exist on IO projects across industries or fields'. To spark and support a move to such comparative research, Yeung's suggestion has some merit. He noted that there is no explicitly articulated methodology for doing IOR research in economic geography. There is therefore a need to coordinate geographical research into IORs that span different countries and/or regions.

The call for longitudinal research into IOR is also increasingly heard, not least in Cropper and Palmer's review of research into change, dynamics, and temporality in IOR research. Brass et al. (2004) in their review of network knowledge emphasized the need to extend IOR research from its base, primarily in cross-sectional studies, and we have seen attempts to develop temporally sophisticated methods (e.g. Moody et al. 2005) for the representation and analysis of networks. Huxham and Beech suggested that 'development of deeper understanding of both the way power is perceived and of the effect that has on inter-party interactions is important to understanding the nature of Inter-organizational relationships, and this includes scope for longitudinal work to investigate how power changes over time and the dynamics of shifting power in the shorter term'.

Use of quantitative methods have been concentrated in particular knowledge and national 'silos'-US strategic management scholarship, etc. The development of more aggregate units of analysis - networks, populations, and communities - starts to open up the possibility of wider usage. As Lomi et al. argue, 'Progress in the evolutionary understanding of Inter-organizational relations is heavily dependent on our ability to develop, specify, and test statistical models for network dynamics ... [Yet] the 
application of these models to the study of Inter-organizational relations is in its infancy.'

Finally, there are challenges not just to method and technique in research, but also to the governance, conduct, and 'moral stance' of researchers that are pointed up by a tendency towards action and towards committed or partisan research. As with the wider field of management inquiry (Hodgkinson 2001; Van de Ven and Johnson 2006; Cummings 2007), there have been a number of calls for more applied, or engaged, research. Huxham and Beech noted the "clear possibility for research on the management of power in practice, preferably within an action research methodology so that attention to practice can be directly incorporated'. Schruijer, too, argued for action research so that real-life problems can be worked with. Both she and Gray concluded that experimental research — whether laboratory or natural — is unlikely to provide a basis for IOR research. Reluctantly, Provan and Sydow agree, though they press for non-randomized quasi-experimental designs as the best alternative to randomized experiments for conducting evaluation research. Gray argues not for one specific design or another, but in the context of discussion intervention approaches for IORs, suggests that ... future researchers might carefully scrutinize each form of intervention to discern its major strengths and weaknesses and the conditions most conducive to it producing its desired ends. Research should also articulate the requisite competencies for individuals attempting such interventions and which interventions are most appropriate for different types of Inter-organizational partnerships. With this additional knowledge, skilful interveners (those equipped with theoretical knowledge about organizational change and unassailable process skills) will have the best chance of making interventions to improve Interorganizational partnerships that have the greatest likelihood of success. Interestingly, the concern with practice has also spread to critical theory. Thus Lotia and Hardy commented that 'a cautious engagement with management practice has emerged', which, following Alvesson and Willmott (1996), is to foster the development of organizations in which communications ... are less distorted by socially oppressive, asymmetrical relations of power'.

\section{IOR: A Silo-ed Field? The Evidence}

It is clear from the above discussion that there are many points of overlap in the many standpoints taken by the chapter authors in this Handbook. We noted in the Introduction to this Handbook, however, that these different research perspectives and their bodies of knowledge over time tended to form specialized 'silos' of IOR research, with scholars rarely building on, contributing to, or even acknowledging the work conducted outside their own particular research silo. Specialization of IOR research in itself certainly is not a bad thing, as it may contribute to greater scrutiny and a deepening of our understanding of IORs. Yet the current seeming fragmentation of IOR research does raise the question of whether it is justified to speak of IOR as a distinct field of scientific enquiry, or whether it represents an array of specialist contributions firmly grounded in other fields (e.g. organization theory, economic geography, institutional theory, research on social capital, etc.) that just happen to focus on the same study object, IORs, but share little else. Before discussing that question in more depth, we first examine the evidence in this Handbook for the continued existence of silo-ed research. 
In our introductory chapter we argued that we believed that the early 'silos' into which IOR research could be deposited were, perhaps, buckling under their own weight. Thus, we were interested to see the extent to which that was evident in this Handbook. For example, would those writing about one particular manifestation of IOEs - for example, alliances or networks - make reference to other manifestations of IORs? We also wondered how frequently those writing about a particular manifestation would rely on theories that were being addressed by authors making contributions in Part III of the Handbook, or would focus to some degree on topics that were being reviewed by authors in Part IV.

Not surprisingly, the results reflect a significant amount of variation. For example, networks were addressed in all chapters in Part II. Strategic alliances, covered in the chapter by Dacin, Reid, and Ring, were also referred to in five other chapters in Part II. By contrast, joint ventures, also covered by Dacin et al., were discussed in only two other chapters addressing empirical manifestations of IOR. As a final example, no other author in Part II made explicit references to industrial districts, covered by Lazerson and Lorenzoni, as a manifestation of IOR.

Six of the chapters in Part III made reference to the use of these theories they had introduced for the study of alliances and joint ventures. By contrast, none of the authors in Part III explicitly referred to use of their theoretical perspectives in studies of non-profit-making organizations and voluntary collaborations. Needless to say, collaborations involving both non-profit-making and voluntary organizations have been explored using disciplines and theories represented in Part III (see e.g. Galaskiewicz 1985; Brass et al. 2004). In contrast, manifestations falling under the general heading of networks were referred to in every chapter in Part III. Almost all of the authors in Parts $\underline{I}$ and $\underline{I I}$ touch on the Part IV issues of trust, power, and knowledge or learning, but social capital, change, dynamics and temporality, intervention methods, and evaluation are rarely mentioned. At face value, this might suggest a breaking down of the silos in the former areas, but this may belie the truth of the matter. Other authors' approaches to these topics are not necessarily consistent with those taken by Bachman and Zaheer, Huxham and Beech, and Nooteboom in Part IV; neither are they consistent with each other. In some contrast, most of the Part IV authors draw on an even wider variety of theoretical bases than are covered in Part $\underline{\text { III }}$, suggesting that drawing insights across theoretical bases may be becoming more acceptable. Two Part IV authors, however, draw only on a more restricted range of theories.

Another way of looking at this is to use the amount of cross-referencing that we find across chapters in this Handbook - both with regard to references to the same publications and to other chapters in this Handbook - as an indicator of the degree of silo-thinking. Although public sector service provision partnerships (see Sandfort and Milward, this volume) arguably share many features and challenges with supply chains and networks in the private sector (see Johnsen et al., this volume) and voluntary and community sector partnerships (see Mandell and Keast, this volume) exhibit commonalities with business alliances and joint ventures (see Dacin et al., this volume), the degree of overlap between the lists of references in the respective chapters is miniscule (two common citations among a total of 262 in the first case, and two of 238 in the second). On the other hand, we see many cross-references in Handbook chapters to the same body of theory or topics, with the social network perspective (see Kenis and Oerlemans, this volume) and institutional theory receiving 
the most, followed by transaction cost theory (see Hennart, this volume) and trust (see Bachmann and Zaheer, this volume).

Yet another indication can be gained by examining the extent to which authors writing on manifestations in Part II recognized the labels given to other manifestations as hiding IOEs that are in essence the same or similar to theirs. For example, did those writing about public service delivery partnerships acknowledge that what they were describing might equally be labelled 'alliances' (and thus, that alliances research might have relevance!).

The answer appears to be that the chapters in Part II rarely explicitly acknowledge similarity, a conclusion not too surprising given that authors were asked to focus on a specific manifestation. However, it is clear that they all tended to see relationships between organizations in the same kinds of terms: driven by a need for resources. There was also a tendency - even for some authors concerned with public or community sector relationships - to frame or orient the discussions of IOEs as falling somewhere along a continuum between markets and hierarchies.

Taking these 'results' together, we may conclude that the silos have not disappeared altogether, but that the walls between them are becoming more permeable. We will return to this line of thinking again in the following discussion of IOR as a field.

\section{Is IOR a Field?}

Our discussion of the development of IOR in the introductory chapter depicted it as growing rather wildly: a jungle with no clear borders and many different beasts living by different rules, wildly competing for survival. In the light of chapters in this Handbook, then, it seems to us that IOR has developed some of the trappings of a distinct field of scientific enquiry yet still lacks others. We mean by field roughly what is implied by the term organizational field; that is, those scholars who 'in the aggregate, constitute a recognized area of institutional life' (DiMaggio and Powell (1983); see McKelvey (2003) for an alternative conceptualization and discussion of what constitutes a 'field' and a 'science' that rests on epistemological criteria). Based on this institutional view, we would suggest that a field of IOR would be rather more like an Italian garden, elegantly designed with its variety strictly regulated, than a jungle. It would exist if there is a community of scholars mutually recognizing one another as contributing to the common scientific undertaking of studying IORs and engaging in research activities leading to some form of institutionalized outcome, such as a shared body of knowledge, dedicated IOR conferences or journals, or IOR entering the curricula of degree programmes. A field of scientific enquiry is different from a discipline, as it uses a discipline's concepts, methods, and basic research focus but applies these to a particular substantive study area. A discipline may therefore comprise a number of different fields of scientific enquiry - sociology, for instance, is home to distinct fields such as the sociology of religion, organizational sociology, economic sociology, urban sociology, and so forth.

Perhaps the most basic precondition for the development of a distinct field of scientific enquiry is that a community of researchers shares a set of core concepts that define the object of study, frame related research questions, and thus bound the field of enquiry. This does not imply that everyone needs to agree on the same definitions for these concepts or on their dimensions; rather, it suffices if scholars 
recognize that by and large they write and speak about the same things and can relate their own work to that of others in the field. As we outlined in the introductory chapter of this Handbook, IOR focuses on the properties and overall patterns of relations between and among organizations pursuing a mutual interest while remaining independent and autonomous in the course of following their separate interests. The basic building blocks constituting IOR thus are notions about the nature of relations (their content, governance, and structure) that exist between and among organizations. While there is some heterogeneity in IOR as to the significant dimensions and their attributes of both relations and relevant features of interrelating organizations, it seems to us that this heterogeneity is a sign of a healthy scientific competition and of the struggle for a better understanding rather than an indication of a fragmented and ill-defined field. After all, even physics with its much longer research tradition and much larger scientific community is still in intense dispute over, and in search of, the number and precise nature of the basic building blocks of matter.

A second condition for the existence of a field of IOR is that the community of researchers engages in a dialogue about their study object that recognizes the possibility of mutual learning. Such dialogue may involve exchange and comparison of concepts, methods, and findings as well as the deliberate juxtaposition of perspectives and knowledge. In these ways, scholars engaged in the field can accumulate, refine, and extend knowledge about IOR, foster mutual learning and, potentially, enrichment between the perspectives and bodies of knowledge. For instance, it becomes possible to clarify the assumptions on which different perspectives are based, to assess the 'direction' of theory in terms of core concepts, units of analysis, questions, and propositions. Moreover, such dialogue may provide some sense of the fruitfulness, or scope, of different contributions to understanding, coverage, and quality of knowledge in different areas.

Our hope is that this Handbook will be instrumental in promoting such dialogue, at least in certain areas. At present, however, it seems that there is still more dialogue within each of the research silos in IOR than across them. It remains difficult to relate contributions from different silos to one another, as each silo has its own theories, concepts, research traditions, and style. Nevertheless, it seems that some boundaries between silos may be more permeable than others. Silos of manifestations of IORs (especially from different sectors) and of particular disciplines appear less permeable than those of theories or themes.

A third and still more far-reaching condition in terms of the development of a field would claim that many scholars should agree on a set of core assumptions, concepts, propositions, methods, and exemplars on which they then routinely base research. In Kuhn's (1962) terms, the field would have established a paradigm and would be engaging in 'normal science'. In addition, we would be able to observe some of the institutional trappings of an established field of scientific enquiry, such as dedicated journals, a tradition of regular conferences on aspects of the field, curricula and chairs at universities that would be devoted to IOR, etc. As this Handbook testifies, research on IOR currently is far from having developed a paradigm, as there does not seem to be an unchallenged set of core assumptions, propositions, and research exemplars that regularly guide IOR research across the various manifestations of IORs, theories, and disciplines. However, IOR nevertheless has fleshed out a few institutional features that characterize a distinct field. For instance, 
the British Academy of Management (BAM) in 1999 established a Special Interest Group on Inter-organizational Relations (SIGIOR) that regularly holds workshops and organizes a track at the BAM Annual Conference; the European Group of Organization Studies (EGOS) since 1994 at its annual conference has regularly devoted a track to IOR and networks that was institutionalized in 1999 as one of EGOS's Standing Working Groups; not least, we should also not forget to mention the fact that a highly reputed publisher has now produced a Handbook, this one, on IOR. Finally, perhaps the most far-reaching requirement is that IOR would be worthy of recognition as a distinct field of scientific enquiry only when (and because) there is less variance exhibited among contributions to IOR than there is between IOR research and the disciplines and theories on which it draws. Thus if IOR were an established field, we would expect to find more conceptual similarities and more overlap in the body of knowledge between, for instance, a discussion of IORs from the perspective of economic geography (see Yeung, this volume) and an account of industrial districts from a business perspective (see Lazerson and Lorenzoni, this volume) than between either chapter and publications on other topics in their respective disciplines.

Given the particular slant of this Handbook towards organization science, it perhaps seems more appropriate, however, to discuss this fourth condition for the existence of a field of IOR in the context of organization science: to what extent and how might research on IOR be distinct from organization science? A look at the table of contents of this Handbook indicates that the degree of overlap between IOR and organization science is indeed almost complete, both with regard to the disciplinary and theoretical perspectives taken up and with respect to research themes. The specificity of IOR rather lies in its focus on particular manifestations at a supra-organizational level of analysis: the study of relations within Inter-organizational entities, their formation, evolution, functioning, and dissolution. However, these manifestations are not the exclusive terrain of IOR. Scholars who would regard themselves primarily as organization scientists would claim too that, say, their research on alliances and joint ventures or on Inter-organizational projects was part of organization science. This overlap in research practice between IOR and organization science is further underscored by the fact that one of four subsections in a recently edited handbook on organizations (Baum 2002) is devoted to the Inter-organizational level of organizational analysis. Conversely, IOR scholars regularly also study the implications of IORs for the organizations involved. It thus seems that to date there is no clear boundary between IOR and organization science other than, perhaps, a difference in the prime level of analysis (IORs versus organizations) on which research concentrates. Yet with regard to research practice, this boundary too seems blurry and highly permeable.

In sum, we conclude that at this point in its development, and from the vantage point of organization science, IOR seems to constitute an emerging sub-field of organization science focusing on the Inter-organizational level of analysis and beginning to develop its own institutional trappings. The empirical and conceptual basis which draws together scholars interested in IORs can be found in a specific focus on questions about the boundaries or identities of Inter-organizational entities, including bilateral and multilateral partnerships and alliances, clusters, groups, and networks, their relational structures, contents, and practices. With regard to these study objects, scholars examine how they emerge, evolve, work, and dissolve as well 
as how they affect the participating organizations, their members and constituencies. With regard to these questions, a dialogue is beginning to emerge, hopefully further fostered by the publication of this Handbook. Despite its distinct research focus and institutionalized dialogue among the community of IOR scholars, however, IOR is not yet a fully developed field of enquiry in the sense that it possesses its own, exclusive concepts, theory, or research themes that are significantly different from those applied elsewhere, particularly in organization science. But does this matter for the potential progress of the study of IORs? Hardly. As IOR's perhaps most important mother discipline, organization science, has successfully demonstrated throughout its history, it can be most fruitful if research endeavours draw on, and learn from, concepts, theories, and methods first developed in other disciplines and fields of scientific enquiry. So even if scholars should simply see IOEs as an interesting study object, an empirical site for investigation of theory and the application of concepts and methods originating in other disciplines or fields of enquiry, they will nevertheless contribute to an enhancement of knowledge about IOR.

\section{References}

Alvesson, M., and Willmott, H. (1996). Making Sense of Management: A Critical Introduction. London: Sage.

Baum, J. A. C. (ed.) (2002). Companion to Organizations. Malden, Mass.: Blackwell Publishing.

Bell, J., den Ouden, B., and Ziggers, G. W. (2006). 'Dynamics of Cooperation: At the Brink of Irrelevance'. Journal of Management Studies, 43: 1607-19. end p.736

PRINTED FROM OXFORD HANDBOOKS ONLINE (www.oxfordhandbooks.com) (C) Copyright Oxford University Press, 2009. All Rights Reserved

Brass, D. J., Galaskiewicz, J., Greve, H., and Tsai, W. (2004). 'Taking Stock of Networks and Organizations: A Multilevel Perspective'. Academy of Management Journal, 47: 795-817.

Burt, R. S. (1997). 'The Contingent Value of Social Capital'. Administrative Science Quarterly, 42: 339-65.

Caplan, T. (1956). 'A Theory of Coalitions in the Triad'. American Sociological Review, 21: 489-93.

Cummings, T. C. (2007). '2006 Presidential Address: Quest for an Engaged Academy'. Academy of Management Review, 32: 355-60.

de Nooy, W., Mrvar, A., and Batagelj, V. (2005). Exploratory Social Network Analysis with Pajek. Cambridge: Cambridge University Press.

DiMaggio, P. J., and Powell, W. W. (1983). 'The Iron Cage Revisited: Institutional Isomorphism and Collective Rationality in Organizational Fields'. American Sociological Review, 48: 147-60.

Ebers, M. (1999). 'The Dynamics of Inter-organizational Relationships'. Research in the Sociology of Organizations, 16: 31-56.

Editors (2006). 'Point-counterpoint: Dynamics of Cooperation'. Journal of Management Studies, 43: 1605-6.

Freeman, L. C. (2004). The Development of Social Network Analysis: A Study in the Sociology of Science. Vancouver: BC Canada/Empirical Press.

Galaskiewicz, J. (1985). 'Interorganizational Relations'. Annual Review of Sociology, 11:281-304.

Gomes-Casseres, B. (1994). 'Group versus Group: How Alliance Networks

Compete'. Harvard Business Review, Jul./Aug.: 62-74. 
Granovetter, M. (2005). 'Business Groups and Social Organization', in N. J. Smelser and R. Swedberg (eds.), The Handbook of Economic Sociology. Princeton: Princeton University Press, 430-50.

Gulati, R., and Gargiulo, M. (1999). 'Where do Inter-organizational Networks Come From?' American Journal of Sociology, 104: 1439-93.

Hennart, J.-F. (2006). 'Alliance Research: Less is More'. Journal of Management Studies, 43: 1621-28.

Hodgkinson, G. (2001). 'Facing the Future: The Nature and Purpose of Management Research Re-assessed'. British Journal of Management, 12, special issue, Dec.: 1-80. Jones, C., Hesterly, W. S., Fladmoe-Linquist, K., and Borgatti, S. P. (1998).

'Professional Service Constellations: How Strategies and Capabilities Influence Collaborative Stability and Change'. Organization Science, 93: 396-410.

Kuhn, T. S. (1962). The Structure of Scientific Revolutions. Chicago: University of Chicago Press.

McKelvey, B. (2003). 'From Fields to Science: Can Organization Studies Make the Transition?' in R. Westwood and S. Clegg (eds.), Debating Organization-PointCounterpoint inOrganization Studies. Malden, Mass.: Blackwell Publishing, 47-73. Moody, J., McFarland, D., and Bender-deMoll, S. (2005). 'Dynamic Network Visualization'. American Journal of Sociology, 110: 1206-41.

Nooteboom, B. (2006). 'Simmel's Treatise on the Triad (1908)'. Journal of Institutional Economics, 2: 365-83.

Obstfeld, D. (2005). 'Social Networks, the Tertius Lungens: Orientation and Involvement in Innovation'. Administrative Science Quarterly, 50: 100-30. end p.737

PRINTED FROM OXFORD HANDBOOKS ONLINE (www.oxfordhandbooks.com) (C) Copyright Oxford University Press, 2009. All Rights Reserved Parkhe, A., Wasserman, S., and Ralston, D. A. (2006). 'New Frontiers in Network Theory Development'. Academy of Management Review, 31: 560-8.

Rowley, T. J., Behrens, D., and Krackhardt, D. (2000). 'Redundant Governance

Structures: An Analysis of Structural and Relational Embeddedness in the Steel and Semiconductor Industries'. Strategic Management Journal, 21: 369-86.

Saxenian, A. (2006). The New Argonauts: Regional Advantage in a Global Economy.Cambridge, Mass.: Harvard University Press.

Simmel, G. (1950). 'The Triad', in K. Wolff (ed.), The Sociology of Georg Simmel. New York: The Free Press, 145-69.

Van de Ven, A. H., and Johnson, P. (2006). 'Knowledge for Theory and Practice'. Academy of Management Review, 31/4: 802-21.

Williamson, O. E. (1985). The Economic Institutions of Capitalism. New York: The Free Press. 